\title{
$\angle$ Research Soure \\ Riedel's Thyroiditis Within an Elderly Patient Revealed by Tracheal Compression: a Case Report
}

\section{Zie Cheick ahmed Traore ( $\square$ cheickil05@gmail.com )}

Universite Alassane Ouattara UFR Sciences Medicales: Universite Alassane Ouattara Unite de Formation et de Recherche Sciences Medicales

\section{Alphonse Aman N'Guiessan}

Université Alassane Ouattara UFR Sciences Médicales: Universite Alassane Ouattara Unite de Formation et de Recherche Sciences Medicales

\section{Zana Ismael Coulibaly}

Universite Felix Houphouet-Boigny

\section{Kouadio Donatien Koffi}

Université Alassane Ouattara UFR Sciences Médicales: Universite Alassane Ouattara Unite de Formation et de Recherche Sciences Medicales

\section{Ibrahiman Toure}

Université Alassane Ouattara UFR Sciences Médicales: Universite Alassane Ouattara Unite de Formation et de Recherche Sciences Medicales

\section{Mohamed Kouyate}

Université Félix Houphouët-Boigny: Universite Felix Houphouet-Boigny

\section{Case Report}

Keywords: Riedel's thyroiditis, Compressive symptoms, Histopathology, Case report

Posted Date: May 11th, 2021

DOI: https://doi.org/10.21203/rs.3.rs-506321/v1

License: (c) (i) This work is licensed under a Creative Commons Attribution 4.0 International License. Read Full License 


\section{Abstract}

Background : Riedel's thyroiditis (RT) is a rare fibrosclerotic disease that affects the thyroid gland and surrounding tissues. The etiology is unknown, and it rarely affects the elderly.

Case Presentation : A 56-year-old man, with no particular medical history, was seen in consultation at the Surgery Department of the Treichville Teaching University Hospital for a painless swelling of the anterior base of the neck. Physical examination showed a patient with inspiratory dyspnea probably due to tracheal compression. The patient underwent a subtotal thyroidectomy because of the clinical symptomatology and the persistence of dyspnea. Macroscopically, the thyroid mass was wellencapsulated, weighed $80 \mathrm{~g}$, and measured $10 \mathrm{~cm} \times 5 \mathrm{~cm} \times 2 \mathrm{~cm}$. After section, we observed whitish fibrous nodules associated with pinkish-brownish band. Histologically, the architecture of thyroid tissue was restructured by dense and diffuse collagenous fibrosis in which rare atrophic thyroid vesicles were found. The fibrous areas were infiltrated by inflammatory elements, including lymphocytes, plasmocytes, and eosinophilic polynuclear cells. No malignant cells were found. Masson's trichrome staining confirmed the fibrous nature of the thyroid tissue, which is essential for the certain diagnosis of Riedel's thyroiditis. There was no postoperative complication

Conclusion : Riedel's thyroiditis is a rare disease that is difficult to diagnose preoperatively despite advances in imaging and fine needle cytology screening methods. Histological examination of the sample confirms the diagnosis of Riedel's thyroiditis. Thyroidectomy is indicated in patients with compression symptoms. Clinicians should suspect Riedel's thyroiditis in patients with a hard thyroid mass with compressive symptoms, despite its rarity.

\section{Introduction}

Riedel's thyroiditis (RT) is a fibro-sclerotic condition affecting the thyroid gland. It is a rare entity of unknown etiology [1, 2]. It was first described by Bernhard Riedel in 1896 based on three cases of hard lesions infiltrating the thyroid gland [3, 4]. Hay et al. [5] identified 30 cases of RT among 5700 cases of thyroidectomy during the period 1920-1984 at the Mayo Clinic in 1985. The incidence rate is estimated to $0.06-1.06$ per 100,000 population. Females are more affected than males [6, 7]. Although no pathognomonic clinical sign defines this disease, compressive signs and endocrine abnormalities may be present [6]. The literature data revealed only 2 cases of RT in black patients from sub-Saharan Africa [8]. In our study, we described a particular case of Riedel's thyroiditis that caused severe tracheal compression within an elderly patient.

\section{Observation}

A 56-year-old man, with no particular medical history, was seen in consultation at the Surgery Department of the Treichville Teaching University Hospital for a painless swelling of the anterior base of the neck. This mass evolved since 2 years and rapidly increased in size during the 5 months prior to hospital 
admission. The increase of the mass tumor was correlated to dysphagia for large boluses of food and sometimes to dyspnea. The dyspnea became increasingly persistent, when the patient was physically active. He received salbutamol with no effect. At emergency room, he presented a moderate dyspnea and a stridor with a cough. He had no sign of thyrotoxicosis. Physical examination showed a patient with inspiratory dyspnea probably due to tracheal compression. We observed an enlarged thyroid gland predominating in the right lobe and measured $12 \mathrm{~cm}$. The thyroid mass was hard, smooth-surfaced, and painless with normal overlying skin. There were no cervical lymph nodes. Carotid pulses were well perceived.

The thyroid function test showed normal levels of thyroid stimulating hormone (TSH) at $0.75 \mu \mathrm{IU} / \mathrm{mL}$, free thyroxine (fT4) at $14.46 \mathrm{pmol} / \mathrm{L}$, and free tri-iodothyronine (fT3) at $5.36 \mathrm{pmol} / \mathrm{L}$. The complete blood count revealed the white blood cell at 5300 cells $/ \mathrm{mm}^{3}$ and the platelet at $120 \times 10^{3} / \mathrm{mm} 3$. Electrocardiography was normal. Thyroid ultrasound displayed heterogeneous thyroid hypertrophy at the expense of the right lobe without any soft tissue abnormalities in the neck.

The fine-needle aspiration cytology showed benign cells arranged in single-layered flaps on an inflammatory background containing rare neutrophils and lymphocytes.

The patient underwent a subtotal thyroidectomy because of the clinical symptomatology and the persistence of dyspnea. The surgical specimen was fixed in $10 \%$ formalin and sent to the Anatomic and Cytologic Pathology Department.

Macroscopically, the thyroid mass was well-encapsulated, weighed $80 \mathrm{~g}$, and measured $10 \mathrm{~cm} \times 5 \mathrm{~cm} \times 2$ $\mathrm{cm}$. After section, we observed whitish fibrous nodules associated with pinkish-brownish bands (Fig. 1). Suspected areas were selected for the standard technique of inclusion in paraffin.

Histologically, the architecture of thyroid tissue was restructured by dense and diffuse collagenous fibrosis in which rare atrophic thyroid vesicles were found (Fig. 2: A, B, and C). The fibrous areas were infiltrated by inflammatory elements, including lymphocytes, plasmocytes, and eosinophilic polynuclear cells. No malignant cells were found. Masson's trichrome staining confirmed the fibrous nature of the thyroid tissue, which is essential for the certain diagnosis of RT (Fig. 2D).

There was no postoperative complication. The patient benefited from tamoxifen $20 \mathrm{mg}$ per day and prednisolone $40 \mathrm{mg}$ per day after surgery. An abdomino-thoracic CT scan was performed to evaluate RT associated with other fibrosis. It did not reveal any systemic evidence of fibrosis.

\section{Discussion}

The Riedel's thyroiditis is rare. Few cases have been reported in the literature data. Initial studies postulated that RT is an autoimmune disorder [9] while others consider it as a local manifestation of the systemic fibrotic process [10]. The incidence rate was estimated to be between 0.06 and 1.06 per 100,000 population. RT occurs primarily in the fifth decade and frequently affects women with a sex ratio of 4 
[11]. In our study, our patient was a male. The etiology of RT remains unknown. Some studies would have shown that there would an association between the RT and the autoimmune mechanism. [12]. For example, specific autoantibodies against the thyroid were detected in many patients with RT. The RT occurs with other autoimmune diseases, such as Hashimoto's thyroiditis, Graves' disease, and pernicious anemia. Our patient had none of these autoimmune diseases. Clinically, there are no pathognomonic features of RT [13]. The most common sign of RT is an enlarged thyroid which is usually hard or even stony. It affects both lobes, grows slowly, and is usually asymptomatic. Obstructive symptoms are common in some patients. Fatourechi et al. [11] have found the following signs: tracheal narrowing (48\%), dysphagia (33\%), vocal cord paralysis (29\%), and pain (24\%). Dyspnea was the major sign in our patient.

Computed tomography and magnetic resonance imaging are relevantin assessing the extent of fibrosis, including the possibility of capsular invasion. Ultrasonography of the thyroid and neck could also be necessary fpr pointing out multiple focal hypoechoic lesions lacking blood flow when evaluated by [14]. The disease activity can be monitored by positron emission tomography with the use of fluorodeoxyglucose [15].

Most patients have normal thyroid function. TSH and free T4 are normal in the vast majority of patients $[16,17]$.

Despite the use of many imaging techniques, RT poses a problem of differential diagnosis with other thyroid diseases that might be inflammatory or tumorous $[6,18,19]$.

The diagnosis of certainty is based on anatomical pathological examination of thyroid biopsies or subtotal or total thyroidectomy specimens.

Macroscopically, this disease generally appears whitish and avascular with firm fibrous nodule of stony consistency and strong adhesions.

Histologically, the predominant lesions were tissue fibrosis, absence of thyroid follicles, and an inflammatory infiltrate of lymphocytes.

Thus, the pathologist will consider some clues which suggest the diagnosis of RT and eliminate other probable etiologies, such as cancer (anaplastic paucicellular thyroid carcinoma), or granulomatous inflammation [22].

In our case, microscopic examination highlighted a parenchyma remodeled by dense and diffuse fibrosis with rare atrophic thyroid vesicles.

Due to the low incidence of Riedel's thyroiditis, adequate management of the disease appears difficult. Most authors have described that RT therapy should aim at treating hypo or hyperthyroidism and control fibrosis-related complications, including airway compression that can lead to recurrent pneumonia, that may be harmful for the patient [13]. In our case, resection of the obstructing segment was indicated. In 
addition, total thyroidectomy is not recommended because of the high possibility of damage to surrounding structures, such as the parathyroid and the laryngeal recurrent nerves.

In refractory cases, low-dose radiotherapy is recommended, however; its effectiveness is questionable [18, 23].

\section{Conclusion}

The Riedel's thyroiditis is rarely disease, characterized by a densely fibrous inflammatory process affecting the entire thyroid gland and sometimes adjacent tissues. Preoperative diagnosis is difficult despite advances in imaging and fine-needle cytology screening methods. The histological examination of the specimen confirms the diagnosis of Riedel's thyroiditis. There are no general guidelines on the treatment of RT. Thyroidectomy is indicated in patients with compressive symptoms, suspicious malignancy, and failure of medical management. Clinicians should suspect RT in patients with a hard thyroid mass with compressive symptoms despite its rarity.

\section{Abbreviations}

RT : Riedel's thyroiditis

TSH : thyroid stimulating hormone

fT4 : free thyroxine

fT3: free tri-iodothyronine

\section{Declarations}

\section{Ethics approval and consent to participate}

Patient provided informed consent.

\section{Consent for publication}

Written informed consent for publication of the clinical details and/or clinical images was obtained from the patient. A copy of the consent form is available for review by the Editor of this journal.

\section{Availability of data and materials}

Data sharing is not applicable to this article as no datasets were generated or analyzed during the current study.

\section{Competing interests}


The authors declare that they have no competing interests.

\section{Fund}

This study is funded from its own resources.

\section{Contributions}

ZCA TRAORE and NA AMAN evaluated the histopathological images and prepared the figures. ZCA TRAORE conceived of this study and drafted the manuscript. ZI COULIBALY and I TOURE provided documents for the literature search All authors read and approved the final manuscript.

\section{Acknowledgements}

We gratefully acknowledge Dr. N'guiessan Alphonse Aman at Alassane Ouattara University for proofreading the discussion.

\section{References}

1. Staurt AE. Thyroïdite de Riedel. Br Med J. 1959; 12: 2-6.

2. Kumar V, Abbas A, Fausto N, Aster JC. Robbins et Cotran Pathologic Basis of Disease. 8 éd. Philadelphie: Saunders, Elsevier; 2010.

3. Riedel BM Vorstellung eines kranken mit chronischer strumitis. Verh Dtsch Ges Chir. 1897; 26: 127129.

4. Riedel BM Die chronische, sur bildung elsenharter tumoren fü hrende entzü ndung der Schilddruse. Verh Dtsch Ges Chir. 1896; 25:101-105.

5. Hay ID. Thyroiditis: A clinical update. Mayo Clin Proc. 1985; 60:836-43.

6. Shahi N, Abdelhamid MF, Jindall M, Awad RW. Riedel's thyroiditis masquerading as anaplastic thyroid carcinoma: a case report. J Med Case Rep. 2010; 4:15.

7. Shafi AA., Saad NB., AlHarthi B. Riedel's thyroiditis as a diagnostic dilemma - A case report and review of the literature. Ann Med Surg. 2020;52:5-9.

8. Arowolo OA, Ige FS, Odujoko O., Agbakwuru. Riedel's thyroiditis in a black African: A case report and review of the literature. Niger J Clin Pract. 2016; 19(4):549-555.

9. Dahlgren M, Khosroshahi A, Nielsen GP, Deshpande V, Stone JH. Riedel's thyroiditis and multifocal fibrosclerosis are part of the IgG4-related systemic disease spectrum. Arthritis Care Res (Hoboken). 2010; 62:1312-8.

10. Papi G, LiVolsi V. Current concepts on Riedel thyroiditis. Am J Clin Pathol 2004;121:S50-63.

11. Fatourechi MM, Hay ID, Mclver B., Sebo TJ, Fatourechi V. Invasive fibrous thyroiditis (Riedel thyroiditis): the mayo clinic experience, 1976-2008. Thyroid. 2011; 21(7):765-772.

12. Kamisawa T, Zen Y, Pillai S, Stone J. H., IgG4-related disease. The Lancet. 2015; 385(9976):1460-71. 
13. Blanco VM, Paez CA, Victoria AM, Arango LG, Arrunategui AM, Escobar J, et al.Riedel's Thyroiditis: Report of Two Cases and Literature Review. Case Report Endocrinol. 2019; 2019: 5130106.

14. Papi G, Corrado S, Cesinaro AM, Novelli L, Smerieri A, Carapezzi C. Riedel's thyroiditis: clinical, pathological and imaging features. Int J Clin Pract. 2002; 56(1):65-67.

15. Lauwyck J, Piette Y, Van Walleghem L, De Geeter F. IgG4-related disease: the utility of (18) F-FDG PET/CT in diagnosis and treatment. Hell J Nucl Med. 2015; 18(1):155-159.

16. Yasmeen T, Khan S, Patel SG, Reeves AW, Gonsh AF, De Bustros A et al. Clinical case seminar: Riedel's thyroiditis: report of a case complicated by spontaneous hypoparathyroidism, recurrent laryngeal nerve injury, and Horner's syndrome. J Clin Endocrinol Metab. 2002; 87(8):3543-3547.

17. Cho MH, Kim CS, Park JS, Kang ES, Ahn CW, Cha BS, et al. Riedel's thyroiditis in a patient with recurrent subacute thyroiditis: a case report and review of the literature. Endocr J. 2007; 54(4):559562.

18. Hennessey J. V. Riedel's thyroiditis: a clinical review. J Clin Endocrinol Metab. 2011; 96(10):30313041.

19. Torres-Montaner A, Beltrán M, Romero de la Osa A, Oliva H. Sarcoma of the thyroid region mimicking Riedel's thyroiditis. J Clin Pathol. 2001; 54:570-572.

20. Kumar N, Gupta R, Sayed S, Moloo Z, Vinayak S, Ahmed M. Difficulties in the diagnosis of Riedel's thyroiditis on aspiration cytology: A case report and brief review of the literature, Diagn Cytopathol. 2019; 47(5):512-516.

21. Harigopal M, Sahoo S, Recant WM, DeMay RM. “Fine-needle aspiration of Riedel's disease: report of a case and review of the literature. Diagn Cytopathol. 2004; 30(3):193-197.

22. Wan SK, Chan JK, Tang SK. Paucicellular Variant of Anaplastic Thyroid Carcinoma: A Mimic of Riedel's Thyroiditis. Am J Clin Pathol 1996; 105(4):388-393.

23. Falhammar H, Juhlin CC, Barner C, Catrina S.-B, Karefylakis C, thyroïdite de Calissendorff J. Riedel's thyroiditis: clinical presentation, treatment and outcomes, Endocrine. 2018; 60(1):185-192.

\section{Figures}




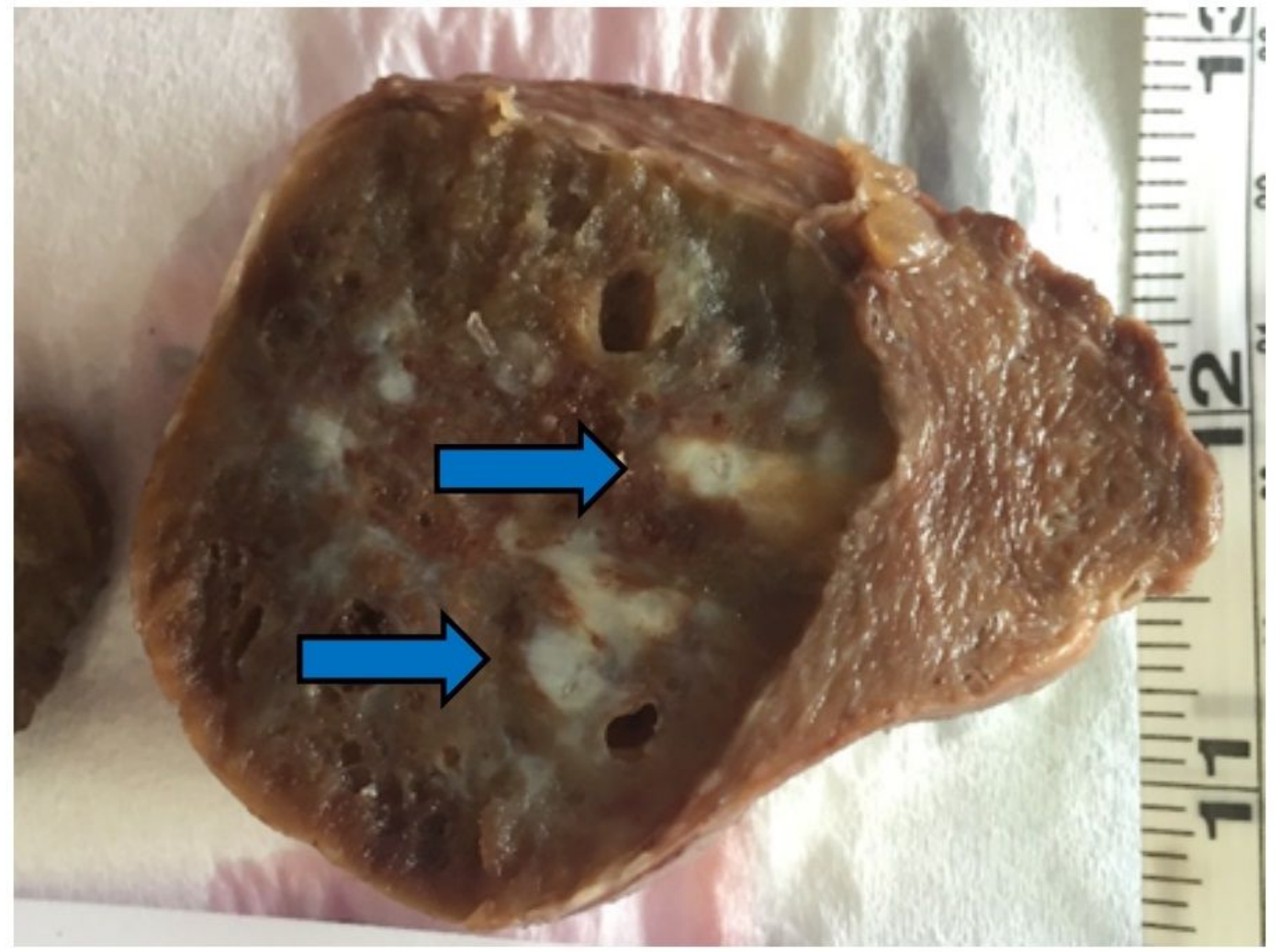

\section{Figure 1}

Thyroid parenchyma showing whitish fibrous nodules (blue arrow). 

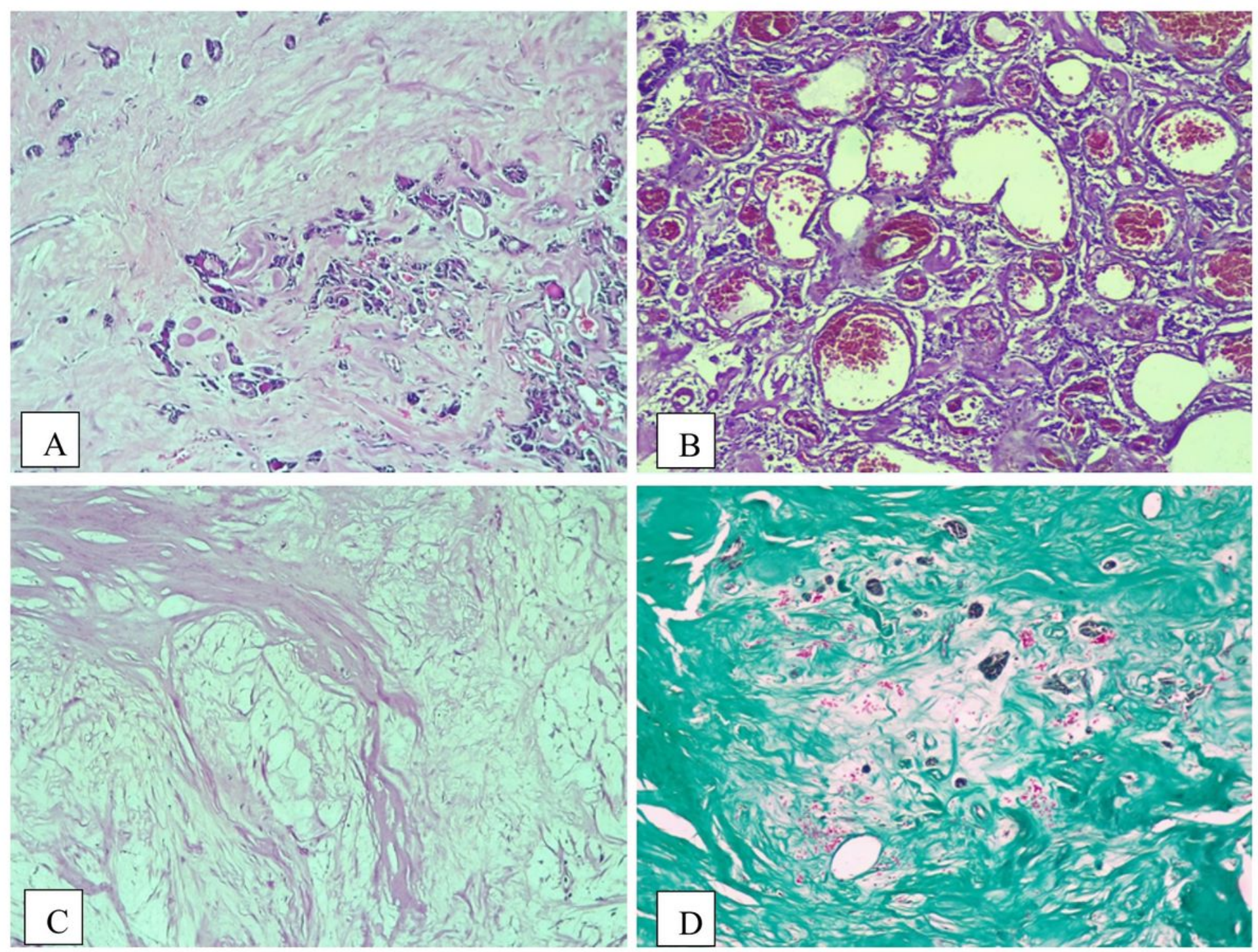

Figure 2

A (HEx100) thyroid vesicles of variable size immersed in dense fibrosis; B (HEx100) lymphoplasmocytic inflammatory infiltrate and fibrosis; C (HEx100) largely hyalinized fibrous tissue replacing the thyroid gland; $D$ (Masson's Trichrome staining $\times 100$ ) dense collagenous fibrosis circumscribing the thyroid vesicles.

\section{Supplementary Files}

This is a list of supplementary files associated with this preprint. Click to download.

- carechecklist.pdf 